\title{
Risky behaviour: a new framework for understanding why young people take risks
}

Lauren Graham ${ }^{1}$, Lucy Jordan ${ }^{2}$, Aisha Hutchinson ${ }^{3}$, Nicole de Wet ${ }^{4}$

${ }^{1}$ Centre for Social Development in Africa, University of Johannesburg

${ }^{2}$ University of Hong Kong and Centre for Social Development in Africa, University of Johannesburg

${ }^{3}$ University of Bedfordshire and Centre for Social Development in Africa, University of Johannesburg

${ }^{4}$ University of the Witwatersrand

\section{Abstract}

Theories of youth risk taking range from the realist to the sociocultural. Much of this theorising, particularly in the field of epidemiology, has been strongly influenced by the Health Belief Framework. More recently, attention has shifted to understanding how young people perceive risk and what makes some of them resilient to risk taking. In this article we develop a framework that brings together diverse theoretical perspectives on youth risk taking. We draw on lessons from across the social science disciplines to inform a conceptual framework incorporating the broad context and internal processes of young people's decisions to take risks. Our Youth Risk Interpretation Framework (Y-RIF) has been developed from insights gained during an ethnographic study conducted in South Africa. We argue that our framework is useful, as it offers new ways of understanding why some young people take risks while others are more cautious. It could be used to inform youth behaviour surveillance research and interventions. However, it will need to be rigorously tested. 


\section{Introduction}

Growing up involves experimenting with new roles and responsibilities, and often involves risk taking. Young people may risk their sexual and reproductive health, they experiment with drugs, they risk their future by dropping out of school, and some get involved in violence and crime. Research focusing on risk behaviour varies according to the perspective taken on the concept of risk: realist (Zinn 2008), neurocognitive (Steinberg 2009) or political legal (McCarthy et al. 2009). The various theories make several basic assumptions. They assume that risk is real and can be objectively defined, that choices are made on an either/or basis (risky behaviour or safe behaviour) or on a cost: benefit basis, and that adolescents and young adults are more prone to risk taking than mature people. They assume that people make rational decisions about risk, based on their perception of the likelihood of a negative outcome (Fischhoff et al. 1993; Kirch 2008). The Health Belief Framework (Rosenstock 1990) is perhaps the most well-known of the frameworks based on such assumptions. According to this framework, the means to reduce risky or health-compromising behaviour is education, to raise awareness of its outcomes. The reasoning is that if young people are better informed, they will be more likely to make rational decisions and less likely to take risks. Mason et al. (2013: 1237) note that such theorising typically argues that if young people 'fail to choose pro-social behaviour', this is due to 'misunderstanding, underestimating risk, lack of neurocognitive 
control, lack of experience, or ignoring the danger'. This realist and rationalist framework has been heavily criticised but it still informs a great deal of thinking about youth risk taking, and prevention and intervention studies globally are mostly based on it.

Some theorists, however, have moved away from the realist view of risk taking and created a sociocultural framework (Lupton 1999; Tulloch and Lupton 2003; Tulloch 2008). From this perspective, risk taking is seen as being shaped by social and cultural norms and expectations. Our definitions of risk will depend on what we perceive as a risk. Epidemiologists, concerned with health including sexual and reproductive health, may see unprotected sex, for example, as extremely risky, while the layperson may not. 'Risk perception does not refer to how 'at risk' a person feels, but rather to the kinds of behaviour they perceive as constituting a risk. Mason et al. (2013: 1237), observing that '[w]hat society may view as a risk may be viewed as a safer choice in the larger sociocultural scheme', consider it imperative to take into account the social context within which decisions about risk are made, if we are to better understand why young people engage in risky behaviour. From a sociocultural perspective, the goal then is to discover how young people define risk and what factors shape their perceptions of risk. The risks they face are socially and culturally embedded, and they take these risks partly as a way of fitting into the social and cultural context (Pilkington 2007b). 
The sociocultural approach to understanding risk taking has been mostly qualitative, drawing on life histories, ethnographies and participatory methods. In our review most studies of youth risk taking in South Africa used either quantitative data, which provides information on vulnerability factors for risk taking, or qualitative data, which provides information about social and cultural contexts and how young people interpret and define risks. Not many have used both. We have therefore created a conceptual framework that connects the two approaches, with the aim of giving researchers a clear picture of the vulnerability factors for risk and at the same time an indepth understanding of the sociocultural factors that may shape the decision to take risks. Our framework helps to distinguish the aspects of life that young people perceive to be risky and to identify the young people who are most likely to take risks. It could be used to inform programmes to help young people manage or reduce risk. Although in this paper we refer predominantly to sexual risk, the framework could be tested to understand its efficacy in explaining other forms of risky behaviour. In addition, while we illustrate the framework with South African examples, we believe that it can be tested in other developing and developed country context to assess its value.. 


\section{Conceptualising the process of risk taking}

This framework, which explains the process of risk taking, the Framework for Youth Risk Interpretation (see Figure 1), takes into account the standard view that the process involves rational decision making, but also incorporates the sociocultural factors that influence the way young people understand risk, and the structural, external and environmental factors that they internalise and process during, or in response to, a particular circumstance or event. The framework reflects the interaction of structural factors, commonly dealt with in quantitative studies, with cognitive decision-making processes, commonly dealt with in qualitative studies. The aim was to provide an integrative framework that can be elaborated and tested by applying mixed methodologies.

$<$ INSERT FIGURE 1 ABOUT HERE $>$

\section{The Youth Risk Interpretation Framework (Y-RIF)}

Past and present contexts

This section deals with Part A in the framework (see Figure 1). The qualitative and participatory research and the sociocultural literature on youth risk makes clear that risk is embedded in social and cultural contexts (Tulloch and Lupton 2003; Tulloch 2008) and 
that what people understand as risk, and how they evaluate and negotiate it is strongly shaped by these contexts. Similarly much quantitative research acknowledges the role of socio-economic contexts in shaping risk outcomes (Tenkorang et al., 2011). In our framework we identify these contexts as developmental, social, cultural, neurocognitive, geographical and structural, which captures a wide but not exhaustive range of contexts that shape risk. The literature deals with many aspects of these contexts, all of which interact and affect each other. Among the determinants of risk-taking behaviour that the literature discusses are poverty (e.g. Bruce 2007; Tenkorang et al. 2011), gender (e.g. Barker 2005; Bhana and Anderson 2013a; Bruce 2007; Carey et al. 2011; Khunou 2006; Langa 2010; O’Sullivan et al. 2006; Richter and Morrell 2006), social networks (e.g. Bauman et al. 2007; Borsari et al. 2007; Farmer et al. 2003; Pelser 2008), values or cultural norms (e.g. Bishop 2011; Swartz 2009, 2011) and personality traits (e.g. Gullone and Moore 2000; Lejuez et al. 2007). However, each of these, while significant, will always function alongside complementary, and sometimes contradictory, determinants. This is not always considered in research that focuses on one or the other.

In addition, contexts are always partly shaped by past events and processes. As contexts in turn partly shape people’s perceptions and actions, historical legacy must be acknowledged. For instance, when we consider the geographical context (one of the six contexts listed in the framework), we can see how people today can be affected by being 
obliged historically to live in a particular location. In South Africa the legacy of apartheid continues to determine where people of different race groups grow up and thus may limit their access to resources and opportunities (Leibbrandt et al. 2010; Ramphele 2002); and in turn make them more vulnerable to risk (Anderson et al. 2007; Bray et al. 2010; Burns and Snow 2012; Swartz 2009). The post-apartheid present also dramatically shapes the lives of young people when it comes to getting an education, (Heaton et al. 2014) a job, (Statistics South Africa 2014) and a sense of belonging (Arnot and Swartz 2012; Swartz et al. 2012). Poor education, lack of employment and a feeling of alienation may all have an effect on a young person's propensity to take risks. When we consider the cultural context, we can again see how history shapes it. For instance, the clash between the traditional view of gender, in which men are dominant, and today's discourse of gender equity may affect young people's decision making, including the decision to take risks (Bhana and Anderson 2013b; Bhana and Pattman 2009; Bowleg et al. 2011; Brown et al. 2005; Hunter 2005; Jewkes and Morrell 2012; O’Sullivan et al. 2006).

Acknowledging past and present contexts in this framework therefore means recognising the influence of the individual's developmental, social, cultural, neurocognitive, geographic and structural history. Here the framework draws on life course theory (Elder et al. 2003), which notes the strong role that people's experiences 
from earliest childhood onwards, and their family and community history, play into shaping their perceptions and actions.

\section{Internalisation of context}

This section deals with Part B in the framework (see Figure 1). Young people constantly process and internalise the contexts described above. For instance, they are faced with a barrage of cultural norms and values, what their peers think and do, media coverage and social policies, each of which inform their thinking, values and beliefs. They do this in many ways; cognitive processing of information and knowledge (Casey et al. 2008; Galvan et al. 2007; Green and Myerson 2004; Myerson et al. 2003; Steinberg 2008), evaluation of values, costs and benefits (Barry 2013; Dhami and Mandel 2012; Reyna and Farley 2006; Reyna and Rivers 2008) and individual autonomy (Choi and Holroyd 2007; Evans et al. 2010; Froyum 2010; Gill, 2009; Jewkes and Morrell 2012). The literature has many views on how risk is negotiated. Psychological perspectives are primarily interested in cognitive processing, economic perspectives on evaluation of costs 
and benefits, and sociocultural perspectives in individual autonomy. Our framework brings these perspectives together to provide a fuller picture.

Since the way that young people understand risk is shaped by 'local social dimensions of class and gender' (Green et al. 2000: 109), the researcher must take these dimensions into account when analysing risk-taking behaviour. Yet the process by which people internalise these dimensions to form the foundation of cognitive processes, including processes to do with risk taking, has received little attention in other conceptual models. Our framework helps to explain the process by showing that the internalisation of these dimensions is a lifelong process, manifested in how people perceive, interpret and act within their contexts; and is the foundation on which decisions to take risks are made.

\section{Events and circumstances}

This section deals with Part C in the framework (see Figure 1). Previous research has dealt, if only implicitly, with the way events and circumstances influence the decision to take risks, but our framework treats this more explicitly by conceptualising this as a 
dynamic process. A particular event or circumstance provides a moment where the past and present contexts and how these have been internalised converge; and in which a young person must interpret the risk that they are faced with. Although the context and the internationalisation of risk richly shape how a risk is interpret, the event or circumstance also plays a role. The event of failing a school subject might change all of the plans an individual had to complete his schooling. Similarly, a persuasive and dominant romantic partner during a time of sexual contact might change all the plans previously made about using a condom during sexual intercourse. The above examples illustrate the way a young person's decision to take a risk will spring from a combination of past and present circumstances and events; in technical terms, from a dynamic relationship between distal and proximal factors.

Interpretation of risk (cognition, preference, agency)

The next part of the framework ( $\mathrm{D}$ in Figure 1) highlights the significance of how young people interpret risk; including aspects of cognition, preference and agency. Young people's past and present contexts (A), how they have internalised these (B), and the events or circumstances they are faced with (C) all influence their decisions about risk; but ultimately how they manage risk in their daily lives will depend on how they interpret risk that arises from a particular event or circumstance (D). This perception will depend 
on past and present contexts (A in Figure 1) but also on how they weigh up the costbenefit of taking a particular risk (preference in D in Figure 1). While peer and family networks play a role in shaping both perceptions of what constitutes risk and vulnerability to engaging in risk (Carey et al. 2011; Markham et al. 2003; Pilkington 2007a; Valle and Tillman 2012), individual factors, particularly related to an individual's representation of self to others (agency in D in Figure 1), also shape perceptions and negotiation of risk (Bishop 2011; House, Bates, et al. 2010; House, Mueller, et al. 2010; Park and Peterson 2006; Swartz 2009). Therefore, a young people's perception of what constitutes a risk, and how at-risk they feel about a particular set of actions or circumstances, is as much a function of their past and present contexts as it is of their process of developing a unique identity (McCall 2003) and what they perceive to be important at a particular time in their lives. Decisions about what risks are 'acceptable' and which to avoid are thus not simply shaped by a risk trade-off or cognitive processing of actions and outcomes. Rather risks are interpreted in complex ways with cognition, preference and agency all playing a greater or lesser role in the eventual decision. As Mason et al. (2013: 1238) note, 'because youth make daily decisions about which risks to approach and which to avoid in accordance with their ever-evolving self-concepts, risk-orientated decision making is just as much a matter of risk refusal as it is a matter of risk taking.' Hence, engagement in risky behaviour, which may have negative health consequences, may also have social 
benefits or carry social risks if avoided. The interpretation of risk ( $D$ in Figure 1) shows how the framework is based on the view that decision making is an exercise of agency that combines rational cognitive processes such as cost-benefit calculation with a nonrational, value-driven or habitual understanding of decision making influenced by underlying social and cultural factors. We contend that decision making is not necessarily a purely rational process, as argued by Weber (1978) and Bourdieu (1990). Examples of this are given below.

\section{Action and outcomes}

This section deals with Part E in the framework (see Figure 1). Our framework captures the complex process of negotiation and decision making that goes on when a person considers whether to take a risk. Ultimately this process results in an action (or lack of action) that leads to an outcome (E in Figure 1). Of course, our framework cannot capture every aspect of the decision-making process, since many of the factors that influence a decision are deeply embedded in a particular individual's life and may not consciously inform this process. To make a decision and act on it may take only a moment, but the decision is nevertheless influenced by the decider's history and context. Taking action (or refraining from taking action) is thus an outcome that may be better anticipated if the 
complexity of the process that led to it can be accurately accounted for in risk behaviour research. This is what our framework aims to achieve.

It is crucial when conceptualising risk taking or risky behaviour not to assume a simple causal, linear relationship between taking a risk or living in a risky situation and a negative outcome. Just because a person engages in some form of risk does not necessarily mean it will have a negative outcome. The concept of resilience is used to explain how the trajectory from risk to a negative outcome can be altered (Ungar 2013), or how the influence of risk can be mitigated or delayed (Fergus and Zimmerman 2005). Our framework does not explicitly include this concept, but we would argue that, because the framework elaborates on the pathways to risk taking, it can contribute to the field of resilience studies and positive youth development.

Summary of framework

A great deal of research on risk taking focuses on structures that shape decision making; we acknowledge that while these play an important role, the exercise of individual agency through decision making plays a significant role in the negotiation and process of risk taking. Our framework fits more closely with the theory of structuration (Giddens, 1991), which, rather than prioritising agency or structure, explicitly incorporates interaction between agency and structure. 
Thus we argue that, contrary to the traditional epidemiological view of youth risk behaviour, risk taking is not merely a trade-off between an objectively defined risk and a safer alternative. Firstly, risks are rarely objectively defined - while ‘experts’ might deem particular kinds of behaviour risky (such as having multiple partners, not using condoms, dropping out of school), people's perceptions of whether such actions are risky are as much a function of social and cultural norms as of individual beliefs. Researchers aiming to measure risk and risk perception should therefore be wary of defining risk externally or 'objectively' and rather take a more youth centred and context specific view of what constitutes risk for young people. The views of a young person's social group are critical to how risk is perceived and these views may shift from context to context. Secondly, the decision to take a risk is based on many kinds of influence - individuals do not make a discrete rational choice between a risky behaviour and a safe one. In a context of poverty the alternatives may be equally risky for the young person - for instance, the risk of having unprotected sex with a partner versus the risk of losing an income source if you choose not to. Rather, a complex set of cultural, social and economic factors shape what the person perceives to be risky and which trade-offs are acceptable at a given time. Taking a risk is rarely an either/or single risk factor decision; risks are taken in a continually changing context of society and everyday life that necessitates continual management of a plethora of alternatives. Risks that are perceived to be most pressing or 
immediate (such as drinking contaminated water because it is difficult to access a source of filtered water) may take precedence over risks that 'experts' view as being of importance (such as not using a condom in a sexual encounter). Mason et al. (2013: 1239) argue that there is a 'requirement to move away from a single risk factor analysis approach to understanding these behaviours as occurring within a lifestyle, and instead to aim to develop a more contextualized understanding of youth lives.’

In the remaining sections of the paper we use examples from our case study material to illustrate the application of our framework.

\section{Application of the Youth Risk Interpretation Framework (Y-RIF)}

To demonstrate the usefulness of our framework we use the example of three participants from an ethnographic study conducted in Johannesburg (REMOVED FOR BLIND REVIEW). We first tell their stories and then use our framework to analyse their reasoning processes when taking or avoiding risks.

These three young people lived in an informal settlement near Johannesburg. They were affected by apartheid era urban planning policies, when such townships were established as essentially labour reserves for nearby industrial and residential areas. However, post-apartheid policies have improved basic infrastructure and services such as 
housing, sanitation, electricity and education in these areas, although inequalities in access to resources persist (Leibbrandt et al. 2010).

The first participant is Teboho (pseudonym), a young African man who grew up with his mother, father and three siblings — what he describes as a solid family background. He was the eldest child and the only boy in the family. His father was employed. This meant that despite the extreme poverty of the area, the family had some income security. They were by no means wealthy and struggled from month to month but had some level of economic stability. All of the children benefited from free education at the local schools although, given apartheid era educational policies, these schools were under-resourced and lacked well-qualified teachers.

In his tenth year of schooling, Teboho's girlfriend fell pregnant with his child. She was also still at school at the time. They had been in what he termed a committed relationship and he loved her. The young woman and he decided to have the baby. Teboho's family felt that it was important for him to accept his commitments as a father and provide for his new family. They felt that they could not take on the additional financial burden of a baby. Weighing his options, Teboho decided that an additional two years of schooling would not benefit him in the long run and he left school to find work. 
From an outsider's point of view, Teboho made two very risky decisions - to have unprotected sex with his girlfriend, and to leave school. How do we explain these decisions?

Our second example is Thabo (pseudonym), a young African man, who grew up with his mother and brother. His mother was a domestic worker and he never knew his father. His mother always insisted that Thabo and his brother getting as good an education as they could at the local township schools and both brothers worked hard at school. Both matriculated with university entrance passes but neither were able to afford tertiary education. Thabo found employment as a factory worker. He wanted to become an engineer and worked closely with engineers in the factory. However, he was frustrated at being stuck in the same position and after five years of employment left his job. At the time of the study he had moved out of his mother's home and was living independently in a shack in an informal settlement. He was involved in the Pentecostal church and was running a youth organisation on a voluntary basis in his community. He said he was a virgin and hoped to remain so until he met his future wife, despite many temptations from the local girls. He aspired to marry a young Christian woman for whom he would pay lobola, and to provide for her and their future children by buying a brick house in the township. He prided himself on being a good role framework to children in the community. 
How do we explain Thabo's resilience to risk taking, given what might be considered a precarious background?

Our third case, Letty (pseudonym), is a young woman, who grew up in the rural areas of Limpopo with her mother, father, siblings and extended family. She described her family as close and supportive. She excelled at school, particularly in mathematics, and dreamed of becoming a social worker or a teacher. In her tenth year of schooling her family sent her to live with her aunt and uncle in Johannesburg to complete her schooling. They felt she would have a better chance of getting a good education and finding a job if she was based in Johannesburg. Letty described her aunt and uncle as supportive but also noted that they did not have the financial means to support an additional child in the house.

Letty left school in her eleventh year, hoping to find work. Shortly thereafter she met her boyfriend, with whom she had two children. Her first son was born when Letty was 18 years old and the second followed three years later. At the time of the study Letty was living alone in a shack in the informal settlement. She had sent her two children to live with her mother in Limpopo. Her partner had left her. She had met someone else and was pregnant with his child. Letty saw herself as a counsellor and support to younger women in the community. She was involved in the Zionist Christian Church, where she was seen as a leader among the young women. 
How do we explain Letty’s decision to have unprotected sex and to leave school despite what presents as a fairly stable family background?

\section{Applying the framework to the study subjects' risk taking or risk avoidance}

Our framework can be applied to a range of youth risk behaviour, but here we focus on sexual risk. Previous studies have focused on identifying and targeting the predictive factors for risky sexual behaviour, such as poverty or economic stability (Choi and Holroyd 2007; Conroy et al. 2010; Dinkelman et al. 2008), household and family support (Markham et al. 2003; Ungar 2013; Valle and Tillman 2012), or individual characteristics such as personality (Gullone and Moore 2000; Lejuez et al. 2007).

If we considered only economic or household predictors, we would expect Teboho and Letty to fare relatively well, and we would be unlikely to predict their engagement in risky behaviour, yet they did take risks. Thabo, on the other hand, came from what would be deemed a more risky background - a poor household with a single parent who was working and therefore absent much of the time and unable to monitor day-to-day behaviour. Yet he managed to avoid taking any major risks. How are we to interpret these contradictions?

Our framework traces the pathways to risk, highlighting the importance of context, both past and present. It accounts for the fact that Teboho, because of apartheid 
urban planning and educational policies, was enrolled in a poorly resourced school, with teachers who were often absent or uninterested, that was unlikely to give him the kind of education that would lead to tertiary education or a decent job. And his family, although economically stable, was poor and struggled to meet financial obligations each month. Where he lived, dropping out of school was not frowned upon but seen rather as an acceptable alternative route to employment, despite the low employment prospects for those without a school-leaving certificate (Statistics South Africa 2015). Culturally, Teboho's background was one that celebrated virility and evidence of masculinity (Barker 2005; Barker and Ricardo 2005; Carey et al. 2011; Hunter 2005; Richter and Morrell 2006; Swartz and Bhana 2010). The family and community expectations of a young man with a child on the way were, above all, that he would provide for the mother and the child. These strong gendered views, along with Teboho's historical, social and geographical context, are part of the background against which his decisions were made.

But on their own they cannot explain his decisions.

While research using population survey data on young people's risk behaviour may be able to show that background factors such as those mentioned above predict young peoples' risk behaviour, it cannot account for how those factors are internalised or trace the resulting pathways that influence decision making (B in Figure 1). Teboho internalised his contexts in various ways. For instance, he subscribed to his community’s 
gender expectations. He wanted to be seen as this kind of man by his community, family and peers. In turn, the way he internalised his context shaped the way he interpreted risk (D in Figure 1) when faced with the event ( $C$ in Figure 1) of a sexual encounter with his girlfriend. Presented with the option of using a condom (agency in D in Figure 1), Teboho had to make a trade-off between demonstrating his virility and minimising the risk of his girlfriend falling pregnant. Virility being an important aspect of his masculine identity, he made the decision (however fleeting in the moment) not to use a condom, with the outcome (E in Figure 1) of a pregnancy.

Similarly, he internalised his context when he weighed up whether he stood a better chance of finding employment immediately or if he completed his schooling (B in Figure 1). The way Teboho internalised this economic context also shaped how he interpreted risk (cognition in D in Figure 1) once faced with the event (C in Figure 1) of his girlfriend's pregnancy. Given that the social and cultural context he had internalised made it important to be seen as a provider, he made the decision (D in Figure 1) to leave school and seek employment (outcome in E in Figure 1).

Exploring Thabo's story provides further insight into the applicability of the framework. Thabo came from the same geographic context, but was raised by a single parent, with far less economic stability and without the support of an extended family. He faced many of the same expectations of masculinity as Teboho did. However, the key 
difference was his membership of a local church, where he was exposed to messages about marriage and monogamy. His past and present context was therefore somewhat different from Teboho’s (A in Figure 1).

Like Teboho, Thabo internalised his context in various ways. In interviews with Thabo it was evident he subscribed to many of the same expectations of masculinity as Teboho did. He said that having multiple sexual partners was acceptable practice and he did not view such behaviour negatively. However, as he had also internalised the church's view of masculinity (B in Figure 1) he said his personal preference was to wait until marriage to engage in sexual relationships. The framework allows us to account for the background factors as well as the internal mechanisms that are responsible for what people internalise. Teboho internalised the culture's dominant discourse of masculinity, and so did Thabo, but he also internalised an alternative discourse (the church's view).

But our framework allows us to go a step further, to understand the (potentially risky) moment of making a decision. It shows that although background factors play a role, depending on how they are internalised, there is still a layer of processing that we need to understand. In the moment of decision making, people consciously or subconsciously, make a trade-off based on their assessment (however brief) of how risky a particular action may be ( $\mathrm{D}$ in Figure 1). That assessment is based on how they have internalised their specific contextual background and what their resulting preferences are. 
Thus, in a moment of sexual decision making, Teboho may have considered the implications of having unprotected sex and decided that not being able to continue with his education because of having to support a pregnant woman was a small risk in a context where a matriculation or diploma certificate would do little for his employment prospects anyway, whereas using a condom would be a big risk because it would undermine his sense of masculinity and the related expectations to demonstrate virility. Understanding this moment of decision making allows us to acknowledge that people's perceptions of what is risky differ. To an outsider, Teboho’s decision making seems irrational - he risks his future for a moment of pleasure. However, based on his perception of what constitutes a risk in relation to his internalised context, we can begin to understand that perhaps Teboho does not perceive leaving school before matriculating as a risk at all. Far more pressing is the risk to his sense of identity as a young man. It is this perception that will influence any trade-offs he considers and ultimately shape the decision he makes. This in turn will result in a particular action which has an outcome. That outcome will feed back into Teboho's context and history, shaping future decisions. If he is praised for his decision or if he perceives that his decision brings benefits such as his peers congratulating him for fathering a child, this may confirm the values of his particular social and cultural context and ultimately confirm the value of his preferences, which may influence later decisions. 
In the case of Thabo, we see similar processes at work. Thabo revealed in an interview that he had been tempted many times to engage in sexual relations with various women who were attracted to him. He emphasised this by showing the researcher text messages and photos that young women had sent to him. When the researcher asked how he was able to avoid engaging in sexual relations with them, he said: 'Ah, but I have something that makes me different.' For Thabo, his reputation as a youth leader and churchgoer was too important to risk for a moment of sexual pleasure. Here we can analyse Thabo's moment of decision making, in which he weighs up the benefit of sexual pleasure against the risk to his reputation. Thus, while the background factors and internalisation of context play an important role in shaping the decision, his agency within that moment plays a bigger role.

Letty's past context was one of relative stability, with a close-knit rural family and success at school. But her geographic context shifted when she migrated to Johannesburg. Migration is associated with increased risk-taking behaviour because of loss of social systems of support (Erulkar et al. 2006). In addition, her social and cultural context was one in which discourses of femininity and women’s agency are very limited, strongly patriarchal, and risky (Bhana and Anderson 2013a; Froyum 2010; Jewkes and Morrell 2012). When it comes to negotiating sexual relationships, these discourses of femininity prioritise male preference, and limit female agency. In addition, her economic 
context of poverty and unemployment increased her vulnerability to risk (Choi and Holroyd 2007; Dinkelman et al. 2008; Tenkorang et al. 2011). How then did she internalise these contexts? What became evident in the researcher's engagement with Letty was that being in a stable partnership had eclipsed her original professional aspirations. A stable partnership would afford her the means to a home, and some income from her partner's meagre earnings. Her preference is not surprising given the realities of poverty and unemployment. It also meant that she would be seen as a 'good wife' reflecting family, church and community values, rather than as a 'hustler' - a derogatory term for young women who engaged in multiple partnerships in the local community. This explains how Letty internalised her historical and more recent context and how this has shaped her cognitive assessment and aspirations for her future (B in Figure 1). It further reveals what she perceived as central preferences for economic security and for her reputation within the community.

When then faced with an event or circumstance (C in Figure 1), Letty used this internalisation of context to interpret the potential risk. Being the ideal romantic partner, with its associated risks, afforded her the opportunity for economic security and a good reputation. She prioritised her partner's sexual preferences, including not using a condom, despite knowing that he was not sexually faithful to her. Although she acknowledged that this was 'the most risky thing she had done', because she was putting herself at risk for 
sexually transmitted infections, she nevertheless weighed this up against the risk of losing her partner (D in Figure 1). In addition, she did not regard unplanned or early childbearing as a risk to avoid; rather, she saw having a child as a way to secure her relationship with her partner - a benefit resulting from engaging in unprotected sex with him.

\section{Conclusion}

The framework presented in this article highlights the complexities of risk negotiation and the importance of finding a way to account adequately for the various drivers of young people's decisions to take risks. Risk has been understood from various perspectives, ranging from rational to sociocultural. Each theoretical standpoint highlights certain aspects of risk decision making, but none singularly adequately accounts for the complexity and multidimensionality of the process. The rational perspective highlights the process of cognition and rational decision making. The economic perspective points to the trade-offs that people make as they decide whether to take a risk. The sociocultural perspective focuses on the role of cultural discourses and norms.

Similarly, various fields of research have approached risk decision making differently and applied research methods that tackle different aspects of the process. Disciplines such as demography and economics that rely primarily on population surveys 
and monitoring systems will view risk taking as a rational process, on the evidence of statistical frameworks. Cognate social science disciplines such as anthropology and cultural sociology are more likely to emphasise the cultural nuances of risk decision making, drawing on in-depth qualitative and ethnographic data. Rather than seeing these as competing perspectives, we value their complementarity. The aim of this article was to bring together insights from across the disciplines to develop a conceptual framework that captures various aspects of risk negotiation.

This framework shows the layers that shape risk taking or risk avoidance, starting with the contextual factors that make young people either vulnerable or resilient to risk taking, including the process of internalisation and subsequent interpretation of risk and risk taking. Our framework demonstrates the value of considering both distal and proximal contexts and of emphasising the role of individual agency in interaction with these contexts.

Although illustrated with South African examples and focused largely on sexual risk, the framework could be applied to other forms of risk taking and in other contexts, provided it is empirically tested. The broad applicability of the framework and its usefulness for assessment and intervention therefore remain to be tested, by being applied to existing quantitative and qualitative data and by eliciting feedback from young people themselves on the accuracy of the framework. 


\section{References}

Anderson, K.G, A.M. Beutel, and B. Maughan-Brown. 2007. "HIV Risk Perceptions and First Sexual Intercourse among Youth in Cape Town, South Africa.” International Family Planning Perspectives 33 (3): 98-105. doi:10.1363/ifpp.33.098.07.

Arnot, M., and S. Swartz. 2012. "Youth Citizenship and the Politics of Belonging: Introducing Contexts, Voices, Imaginaries.” Comparative Education 48 (1): 1-10. doi:10.1080/03050068.2011.637759.

Barker, G.T. 2005. Dying to Be Men: Youth, Masculinity and Social Exclusion. Abingdon: Routledge.

Barker, G., and C. Ricardo. 2005. "Young Men and the Construction of Masculinity in Sub-Saharan Africa: Implications for HIV/AIDS, Conflict and Violence.” Social Development Papers: Conflict Prevention and Reconstruction 26. Washington, DC: World Bank.

Barry, M. 2013. "Rational Choice and Responsibilisation in Youth Justice in Scotland: Whose Evidence Matters in Evidence-Based Policy?” Howard Journal of Criminal Justice 52 (4): 347-364. doi:10.1111/hojo.12019.

Bauman, K.E., R. Faris, S.T. Ennett, A. Hussong, and V.A. Foshee. 2007. “Adding Valued Data to Social Network Measures: Does It Add to Associations with Adolescent Substance Use?” Social Networks 29 (1): 1-10. doi:10.1016/j.socnet.2005.11.007.

Bhana, D., and B. Anderson. 2013a. "Gender, Relationship Dynamics and South African Girls’ Vulnerability to Sexual Risk.” African Journal of AIDS Research 12 (1): 2531. doi:10.2989/16085906.2013.815408.

Bhana, D., and B. Anderson. 2013b. "Desire and Constraint in the Construction of South African Teenage Women's Sexualities.” Sexualities 16 (5-6): 548-564. doi:10.1177/1363460713487366.

Bhana, D., and R. Pattman. 2009. "Researching South African Youth, Gender and Sexuality within the Context of HIV/AIDS.” Development 52 (1): 68.

Bishop, E. 2011. “'I’m Not a Real Risk-Taker’: Moral Identity Construction and SexualRisk Perceptions among a Group of Young Rural Tasmanians.” Sex Education 11 (4): 401-417. doi:10.1080/14681811.2011.595238. 
Borsari, B., J.G. Murphy, and N.P. Barnett. 2007. "Predictors of Alcohol Use during the First Year of College: Implications for Prevention.” Addictive Behaviors 32 (10): 2062-2086. doi:10.1016/j.addbeh.2007.01.017.

Bourdieu, P. 1990. In Other Words: Essays Towards a Reflexive Sociology. Stanford: Stanford University Press.

Bowleg, L., M. Teti, J.S. Massie, A. Patel, D.J. Malebranche, and J.M. Tschann. 2011. ““What Does It Take to Be a Man? What Is a Real Man?’: Ideologies of Masculinity and HIV Sexual Risk among Black Heterosexual Men.” Culture, Health \& Sexuality 13 (5): 545-559. doi:10.1080/13691058.2011.556201.

Bray, R., I. Gooskens, S. Moses, L. Kahn, and J. Seekings. 2010. Growing up in the New South Africa: Childhood and Adolescence in Post-Apartheid Cape Town. Cape Town: HSRC (Human Sciences Research Council) Press.

http://www.hsrcpress.ac.za/product.php?productid=2276\&cat=1\&page=1

Brown, J., J. Sorrell, and M. Raffaelli. 2005. “An Exploratory Study of Constructions of Masculinity, Sexuality and HIV/AIDS in Namibia, Southern Africa." Culture, Health \& Sexuality 7 (6): 585-598. doi:10.1080/13691050500250198.

Bruce, D. 2007. “To Be Someone: Status Insecurity and Violence in South Africa.” In Someone Stole My Smile: An Exploration into the Causes of Youth Violence in South Africa, edited by P. Burton, 57-68. CJCP Monograph Series 3. Cape Town: Centre for Justice and Crime Prevention.

Burns, P.A., and R.C. Snow. 2012. "The Built Environment \& the Impact of Neighborhood Characteristics on Youth Sexual Risk Behavior in Cape Town, South Africa." Health \& Place 18 (5): 1088-1100. doi:10.1016/j.healthplace.2012.04.013.

Carey, K., L. Scott-Sheldon, M. Carey, D. Cain, R. Mlobeli, R. Vermaak, J. Mthembu, L. Simbayi, and S. Kalichman. 2011. “Community Norms for HIV Risk Behaviors among Men in a South African Township.” Journal of Behavioral Medicine 34 (1): 32-40. doi:10.1007/s10865-010-9284-6.

Casey, B.J., S. Getz, and A. Galvan. 2008. “The Adolescent Brain.” Developmental Review 28 (1): 62-77. doi:10.1016/j.dr.2007.08.003.

Choi, S.Y.P., and E. Holroyd. 2007. “The Influence of Power, Poverty and Agency in the Negotiation of Condom Use for Female Sex Workers in Mainland China.” Culture, Health \& Sexuality 9 (5): 489-503. doi:10.1080/13691050701220446. 
Conroy, K., M. Sandel, and B. Zuckerman. 2010. "Poverty Grown Up: How Childhood Socioeconomic Status Impacts Adult Health.” Journal of Developmental \& Behavioral Pediatrics 31 (2): 154-160. doi:10.1097/DBP.0b013e3181c21a1b.

Dhami, M.K., and D.R. Mandel. 2012. "Forecasted Risk Taking in Youth: Evidence for a Bounded-Rationality Perspective.” Synthese 189 (1): 161-171. doi:10.1007/s11229-012-0110-2.

Dinkelman, T., D. Lam, and M. Leibbrandt. 2008. “Linking Poverty and Income Shocks to Risky Sexual Behaviour: Evidence from a Panel Study of Young Adults in Cape Town." South African Journal of Economics 76 (May): S52-S74. doi:10.1111/j.1813-6982.2008.00170.x.

Elder, G.H, M. Kirkpatrick Johnson, and R. Crosnoe. 2003. “The Emergence and Development of Life Course Theory.” In Handbook of the Life Course, edited by J.T. Mortimer and M.J. Shanahan, 3-19. Handbooks of Sociology and Social Research. New York: Springer. http://link.springer.com/chapter/10.1007/978-0306-48247-2_1.

Erulkar, A., T. Mekbib, N. Simie, and T. Gulema. 2006. “Migration and Vulnerability among Adolescents in Slum Areas of Addis Ababa, Ethiopia.” Journal of Youth Studies 07/2006; 9 (3): 361-374.

Evans, A., S. Riley, and A. Shankar. 2010. “Technologies of Sexiness: Theorizing Women's Engagement in the Sexualization of Culture.” Feminism \& Psychology 20 (1): 114-131. doi:10.1177/0959353509351854.

Farmer, T.W., D.B. Estell, M.-C. Leung, H. Trott, J. Bishop, and B.D. Cairns. 2003. "Individual Characteristics, Early Adolescent Peer Affiliations, and School Dropout: An Examination of Aggressive and Popular Group Types.” Journal of School Psychology 41 (3): 217-232. doi:10.1016/S0022-4405(03)00046-3.

Fergus, S., and M.A. Zimmerman. 2005. “Adolescent Resilience: A Framework for Understanding Healthy Development in the Face of Risk.” Annual Review of Public Health 26 (1): 399-419. doi:10.1146/annurev.publhealth.26.021304.144357.

Fischhoff, B., A. Bostrom, and M.J. Quadrel. 1993. "Risk Perception and Communication.” Annual Review of Public Health 14 (1): 183-203. doi:10.1146/annurev.pu.14.050193.001151. 
Froyum, C.M. 2010. “Making 'Good Girls’: Sexual Agency in the Sexuality Education of Low-Income Black Girls.” Culture, Health \& Sexuality 12 (1): 59-72. doi:10.1080/13691050903272583.

Galvan, A., T. Hare, H. Voss, G. Glover, and B.J. Casey. 2007. "Risk-Taking and the Adolescent Brain: Who Is at Risk?” Developmental Science 10 (2): F8-F14. doi:10.1111/j.1467-7687.2006.00579.x.

Giddens, A. 1991. Modernity and Self-Identity : Self and Society in the Late Modern Age. Stanford: Stanford University Press.

Green, E., W. Mitchell, and R. Bunton. 2000. "Contextualizing Risk and Danger: An Analysis of Young People’s Perceptions of Risk.” Journal of Youth Studies 3 (2): 109-126. doi:10.1080/713684369.

Green, L., and J. Myerson. 2004. “A Discounting Framework for Choice With Delayed and Probabilistic Rewards.” Psychological Bulletin 130 (5): 769-792. doi:10.1037/0033-2909.130.5.769.

Gullone, E., and S. Moore. 2000. “Adolescent Risk-Taking and the Five-Factor Framework of Personality.” Journal of Adolescence 23 (4): 393-407. doi:10.1006/jado.2000.0327.

Heaton, T.B., A.Y. Amoateng, and M. Dufur. 2014. "Race Differences in Educational Attainment of Youth Aged 7-18 in Post-Apartheid South Africa: The Role of Family Structure, Resources and School Quality.” South African Review of Sociology 45 (1): 101-121. doi:10.1080/21528586.2014.887917.

House, L.D., J. Bates, C.M. Markham, and C. Lesesne. 2010. “Competence as a Predictor of Sexual and Reproductive Health Outcomes for Youth: A Systematic Review.” Journal of Adolescent Health 46 (3): doi:10.1016/j.jadohealth.2009.12.003.

House, L.D., T. Mueller, B. Reininger, K. Brown, and C.M. Markham. 2010. "Character as a Predictor of Reproductive Health Outcomes for Youth: A Systematic Review.” Journal of Adolescent Health 46 (3, Supplement): S59-S74. doi:10.1016/j.jadohealth.2009.11.218.

Hunter, M. 2005. "Cultural Politics and Masculinities: Multiple-Partners in Historical Perspective in KwaZulu-Natal.” Culture, Health \& Sexuality 7 (4): 389-403. doi:10.1080/13691050412331293458. 
Jewkes, R., and R. Morrell. 2012. "Sexuality and the Limits of Agency among South African Teenage Women: Theorising Femininities and Their Connections to HIV Risk Practises.” Social Science \& Medicine 74 (11): 1729-1737. doi:10.1016/j.socscimed.2011.05.020.

Khunou, G. 2006. "Maintenance and Changing Masculinities as Sources of Gender Conflict in Contemporary Johannesburg.” PhD Thesis. Johannesburg: University of the Witwatersrand.

Kirch, W. 2008. Encyclopedia of Public Health. London: Springer.

Langa, M. 2010. “Contested Multiple Voices of Young Masculinities amongst Adolescent Boys in Alexandra Township, South Africa.” Journal of Child \& Adolescent Mental Health 22 (1): 1-13. doi:10.2989/17280583.2010.493654.

Leibbrandt, M., I. Woolard, A. Finn, and J. Argent. 2010. "Trends in South African Income Distribution and Poverty since the Fall of Apartheid”. OECD (Organisation for Economic Co-operation and Development). http://ideas.repec.org/p/oec/elsaab/101-en.html

Lejuez, C.W., W. Aklin, S. Daughters, M. Zvolensky, C. Kahler, and M. Gwadz. 2007. "Reliability and Validity of the Youth Version of the Balloon Analogue Risk Task (BART-Y) in the Assessment of Risk-Taking Behavior Among Inner-City Adolescents.” Journal of Clinical Child \& Adolescent Psychology 36 (1): 106-111. doi:10.1080/15374410709336573.

Lupton, D. 1999. Risk and Sociocultural Theory: New Directions and Perspectives. Cambridge: Cambridge University Press.

Markham, C.M., S.R. Tortolero, S.L. Escobar-Chaves, G.S. Parcel, R. Harrist, and R.C. Addy. 2003. "Family Connectedness and Sexual Risk-Taking Among Urban Youth Attending Alternative High Schools.” Perspectives on Sexual \& Reproductive Health 35 (4): 174-179.

Mason, M.J., J.F. Tanner, M. Piacentini, D. Freeman, T. Anastasia, W. Batat, W. Boland, et al. 2013. “Advancing a Participatory Approach for Youth Risk Behavior: Foundations, Distinctions, and Research Directions.” Journal of Business Research 66 (8): 1235-1241. doi:10.1016/j.jbusres.2012.08.017.

McCall, G.J. 2003. “The Me and the Not-Me: Positive and Negative Poles of Identity.” In Advances in Identity Theory and Research, edited by P.J Burke, T.J Owens, R. T. Serpe, and P.C. Thoits, 11-25. New York: Plenum. 
McCarthy, W.J., R. Mistry, Y. Lu, M. Patel, H. Zheng, and B. Dietsch. 2009. "Density of Tobacco Retailers Near Schools: Effects on Tobacco Use Among Students.” American Journal of Public Health 99 (11): 2006-2013. doi:10.2105/AJPH.2008.145128.

Myerson, J., L. Green, J. Scott Hanson, D.D Holt, and S.J. Estle. 2003. “Discounting Delayed and Probabilistic Rewards: Processes and Traits.” Journal of Economic Psychology 24 (5): 619-635. doi:10.1016/S0167-4870(03)00005-9.

O’Sullivan, L.F., A. Harrison, R. Morrell, A. Monroe-Wise, and M. Kubeka. 2006. "Gender Dynamics in the Primary Sexual Relationships of Young Rural South African Women and Men.” Culture, Health \& Sexuality 8 (2): 99-113. doi:10.1080/13691050600665048.

Park, N., and C. Peterson. 2006. "Moral Competence and Character Strengths among Adolescents: The Development and Validation of the Values in Action Inventory of Strengths for Youth.” Journal of Adolescence 29 (6): 891-909. doi:10.1016/j.adolescence.2006.04.011.

Pelser, E. 2008. "Learning to Be Lost: Youth Crime in South Africa.” Discussion Paper for the HSRC (Human Sciences Research Council) Youth Policy Initiative, Reserve Bank, South $\quad 13$ Africa, May, 2008. http://cjcp.skinthecat.co.za/articlesPDF/25/HSRC\%20Youth\%20Crime\%20Discu ssion\%20Paper\%282\%29.pdf

Pilkington, H. 2007a. "Beyond 'Peer Pressure': Rethinking Drug Use and 'Youth Culture.” International Journal of Drug Policy 18 (3): 213-224. doi:10.1016/j.drugpo.2006.08.003.

Pilkington, H. 2007b. “In Good Company: Risk, Security and Choice in Young People’s Drug Decisions.” Sociological Review 55 (2): 373-392. doi:10.1111/j.1467954X.2007.00710.x.

Ramphele, M. 2002. Steering by the Stars: Being Young in South Africa. Cape Town: Tafelberg.

Reyna, V.F., and F. Farley. 2006. "Risk and Rationality in Adolescent Decision Making: Implications for Theory, Practice, and Public Policy.” Psychological Science in the Public Interest 7 (1): 1-44. doi:10.1111/j.1529-1006.2006.00026.x.

Reyna, V.F., and S.E. Rivers. 2008. “Current Theories of Risk and Rational Decision Making.” Developmental Review 28 (1): 1-11. doi:10.1016/j.dr.2008.01.002. 
Richter, L.M., and R. Morrell. 2006. Baba: Men and Fatherhood in South Africa. Cape Town: HSRC (Human Sciences Research Council) Press.

Rosenstock, I. 1990. "The Health Belief Framework: Explaining Health Behaviour through Expectancies.” In Health Behaviour and Health Education: Theory, Research and Practice, edited by K. Glanz, F. Lewis, and B. Rimer, 39-62. JosseyBass Health Series. San Francisco: Jossey-Bass.

Statistics South Africa. 2015. "National and Provincial Labour Market: Youth: Q1: 2008 - Q1: 2015.” Pretoria: Statistics South Africa.

Steinberg, L. 2008. “A Social Neuroscience Perspective on Adolescent Risk-Taking.” Developmental Review 28 (1): 78-106. doi:10.1016/j.dr.2007.08.002.

Steinberg, L. 2009. "Should the Science of Adolescent Brain Development Inform Public Policy?” American Psychologist 64 (8): 739-50. doi:10.1037/0003-066X.64.8.739.

Swartz, S. 2009. Ikasi: The Moral Ecology of South Africa's Township Youth. Johannesburg: Wits University Press.

Swartz, S. 2011. "Being Turned inside out: Researching Youth, Morality and Restitution from the Global South.” Journal of Moral Education 40 (3): 407-415. doi:10.1080/03057240.2011.596344.

Swartz, S., and A. Bhana. 2010. Teenage Tata: Voices of Young Fathers in South Africa. Cape Town: HSRC (Human Sciences Research Council) Press.

Swartz, S., J.H. Harding, and A. de Lannoy. 2012. "Ikasi Style and the Quiet Violence of Dreams: A Critique of Youth Belonging in Post-Apartheid South Africa.” Comparative Education 48 (1): 27-40. doi:10.1080/03050068.2011.637761.

Tenkorang, E.Y., E. Maticka-Tyndale, and F. Rajulton. 2011. “A Multi-Level Analysis of Risk Perception, Poverty and Sexual Risk-Taking among Young People in Cape Town, South Africa." Health \& Place 17 (2): 525-535. doi:10.1016/j.healthplace.2010.12.009.

Tulloch, J. 2008. “Culture and Risk.” In Social Theories of Risk and Uncertainty, edited by J.O. Zinn. Chichester, West Sussex: Wiley-Blackwell.

Tulloch, P., and D. Lupton. 2003. Risk and Everyday Life. London: SAGE.

Ungar, M. 2013. “Family Resilience and At-Risk Youth.” In Handbook of Family Resilience, edited by D.S. Becvar, 137-152. New York: Springer. http://link.springer.com/chapter/10.1007/978-1-4614-3917-2_9. 
Valle, G., and K.H. Tillman. 2012. “Childhood Family Structure and Romantic Relationships During the Transition to Adulthood.” Journal of Family Issues 35: 97-124. doi:10.1177/0192513X12463555.

Weber, M. 1978. Economy and Society: An Outline of Interpretive Sociology. Berkeley: University of California Press.

Zinn, J.O. 2008. Social Theories of Risk and Uncertainty: An Introduction. Malden: Blackwell. 